\title{
MORFOMETRIA CORPÓREA E CARACTERIZAÇÃO DO SÊMEN EM VEADO SAMBAR (CERVUS UNICOLOR) NA ESTAÇÃO REPRODUTIVA
}

\author{
Ellyn Amanda Fonseca Martins ${ }^{1}$; Luis Roberto Almeida Gabriel Filho ${ }^{2}$; Marcelo George Mungai \\ Chacur $^{1}$
}

${ }^{1}$ Universidade do Oeste Paulista -UNOESTE, Pres. Prudente, SP. ${ }^{2}$ Universidade Estadual Paulista - UNESP, Tupã, SP. Email: ea.vet@ig.com.br chacur@unoeste.br

\section{RESUMO}

Objetivou-se avaliar a morfometria corpórea e o quadro espermático em cervos criados em cativeiro. Quatro machos com idades entre 12 e 36 meses foram utilizados e em quatro momentos com intervalos de sete dias foram submetidos à colheita de sêmen e mensuradas características corpóreas, obtendo-se: peso $(60,5$ a 89,0 kg) e o índice de massa corporal $(93,07$ $\mathrm{kg} / \mathrm{m}^{2}$ a $126,56 \mathrm{~kg} / \mathrm{m}^{2}$ ). Foram realizadas quatro colheitas de sêmen por animal, no mês de novembro (primavera), com intervalo de sete dias, por meio de eletroejaculador, sob efeito de anestesia geral. Obteve-se os valores de: volume do ejaculado $(0,50 \pm 0,35 \mathrm{~mL}$ a $0,75 \pm 0,28 \mathrm{~mL})$, motilidade espermática $(87,75 \pm 4,78 \%$ a $90,00 \pm 7,07 \%)$, e defeitos espermáticos totais $(17,25 \pm 5,81 \%$ a $47,72 \pm 17,55 \%)$. Boa qualidade espermática foi observada na primavera, nas três primeiras colheitas: volume do ejaculado $(0,50 \pm 0,35 \mathrm{~mL}$ a $0,75 \pm 0,28 \mathrm{~mL})$, motilidade espermática $(83,75 \pm 4,78 \%$ a $90,00 \pm 7,07 \%)$ e defeitos espermáticos totais $(17,25 \pm 5,81 \%$ a $20,41 \pm 2,74)$. As características dos ejaculados não diferiram entre as colheitas sucessivas, exceto a morfologia espermática que se elevou na quarta colheita $(47,72 \pm 17,55 \%)$, possivelmente devido ao estresse das contenções semanais sucessivas.

Palavras-chave: veado sambar, Cervus unicolor, morfometria corpórea, sêmen, reprodução.

\section{BODY MORPHOMETRY AND SEMEN CHARACTERISTICS IN SAMBAR DEER (Cervus unicolor) IN REPRODUCTIVE SEASON}

\begin{abstract}
This study aimed to evaluate body morphology and sperm framework deer raised in captivity. Four males aged between 12 and 36 months were used and four times with seven day intervals were submitted to harvest semen and measured bodily features, obtaining: weight (60.5 to $89.0 \mathrm{~kg})$ and the index body weight $\left(93.07 \mathrm{~kg} / \mathrm{m} 2\right.$ to $126.56 \mathrm{~kg} / \mathrm{m}^{2}$ ). Four per animal semen samples were collected in the month of November (spring), with seven day intervals through eletroejaculator under general anesthesia. Obtained values: ejaculate volume $(\mathrm{ml} 0.50 \pm 0.350 .28 \pm 0.75 \mathrm{~mL})$, motility $(87.75 \pm 4.78 \%$ and $90.00 \pm 7.07 \%)$, and total sperm defects $(17.25 \pm 5.81 \%$ and $47.72 \pm$ $17.55 \%)$. Good sperm quality was observed in the spring, in the first three crops: ejaculate volume $(0.50 \pm 0.35 \mathrm{~mL}$ to $0.75 \pm 0.28 \mathrm{~mL}$ ), sperm motility $(83.75 \pm 4.78 \%$ to $90,00 \pm 7.07 \%)$ and total sperm defects $(17.25 \pm 5.81 \%$ and $20.41 \pm 2.74)$. The characteristics of ejaculated did not differ between successive crops, except sperm morphology that rose in the fourth harvest $(47.72 \pm$ $17.55 \%)$, possibly due to stress from successive weekly contentions.
\end{abstract}

Keywords: sambar deer, Cervus unicolor, body morphometry, semen, reproduction 


\section{INTRODUÇÃO}

A família Cervídae, da qual fazem parte os veados, pertence à ordem Artiodactyla (Maia, 1993). Os Cervus unicolor, conhecido como cervo sambar, são os ruminantes selvagens mais disseminados no mundo (Van Soest, 1994). Porém, pouco se sabe a respeito do comportamento reprodutivo dos cervos nas condições de vida livre, e em cativeiro. O exame andrológico é uma das técnicas mais utilizadas pelos médicos veterinários para avaliar a fertilidade, caracteriza-se por exame clínico, medida de circunferência escrotal e avaliação do espermatozoide para motilidade, vigor, turbilhonamento, concentração e morfologia (Salvador et al., 2002). As avaliações clínicas e seminais são fundamentais para classificação e prognóstico da função reprodutiva (Vale Filho et al., 1986). O plasma seminal serve como veículo para os espermatozoides ejaculados, consistindo em uma mistura de secreções dos testículos e glândulas sexuais acessórias, com função carreadora dos gametas masculinos até o trato genital feminino viabilizando a fertilização (Manjunath, 1987; Einspanier, 1991). As características fisiológicas reprodutivas podem sofrer alterações devido ao estresse em cativeiro (Pocay et al., 2001). Devido à escassez de dados na literatura nacional, pouco se sabe com relação à esfera reprodutiva em cervos exóticos mantidos em cativeiro (Cervus unicolor). O objetivo do trabalho foi avaliar a morfometria corpórea e o quadro espermático, pois informações obtidas de animais mantidos em cativeiro com um bom escrore corporal, condições nutricionais adequadas podem ser úteis para se traçar estratégias de manejo reprodutivo que está intimamente relacionado às boas condições nutricional do animal (Paranhos da Costa, 2000).

\section{MATERIAL E MÉTODOS}

Animais e local do experimento

Foram utilizados quatro $(n=4)$ cervos sambar (Cervus unicolor) machos, identificados com as letras A e B com idade de 36 meses e pesos de 89 e $95 \mathrm{Kg}$, respectivamente, C com idade de 18 meses e peso de $81 \mathrm{~kg}$ e D com 12 meses pesando 60,5 Kg, criados em cativeiro (Zoológico de Presidente Prudente - SP, com latitude de 2129'50"S; longitude de 4914'2"W e altitude de $475 \mathrm{~m}$. Os animais recebiam alimentação balanceada com frutas e legumes: laranja, maçã, banana, mamão, beterraba, cenoura e abóbora em proporções iguais $(8 \mathrm{Kg})$; sal mineral, ração para bovinos ( $18 \%$ proteínas), capim colonião Panicum maximum e água ad libitum. 0 experimento foi realizado no mês de novembro de 2010 (primavera) e os fatores climáticos aferidos na primavera $(P)$ foram: temperatura ambiente média $(24,5 \circ C)$, insolação $(239,74 h)$, índice pluviométrico cumulativo $(126 \mathrm{~mm})$ e umidade relativa do ar (80,6\%). O clima é 
caracterizado pela presença de massas de ar Tropicais e Polares, com estação de inverno fria e seca, e verão quente e chuvoso.

\section{Colheita e processamento das amostras}

Antecedendo as colheitas, foram realizadas prévias contenções químicas, administrando por via intramuscular zoletil associado à xilazina, obedecendo sempre a sequência do animal $A, B$, C e D, e utilizando um intervalo em média de 20 minutos entre colheitas. Os animais foram pesados e a altura da cernelha mensurada para a obtenção do índice de massa corpórea (IMC),

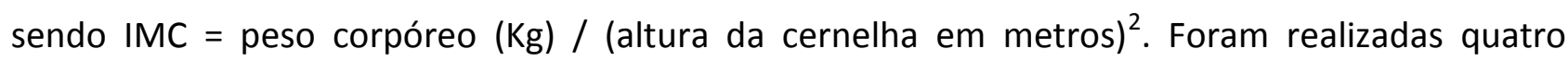
colheitas de sêmen por animal, com intervalo de sete dias, por meio de eletroejaculador (Autoejac ${ }^{\circledR}$, Neovet, Brasil) com probe retal para ovinos, a qual foi introduzido no reto do animal, após prévia lubrificação, sob efeito de anestesia geral, com estímulos elétricos de 2 a 3 segundos, seguidos por igual tempo de repouso. As amostras de sêmen foram analisadas com relação às características quantitativas e qualitativas por exame andrológico: volume ( $\mathrm{mL})$, cor, aspecto, motilidade espermática (\%), vigor espermático (1 a 5), turbilhonamento (1 a 5), concentração espermática $\left(\times 10^{6} / \mathrm{mL}\right)$, sendo os defeitos espermáticos maiores, menores e totais (\%) visualizados em lâminas coradas com panotipo rápido. Após última colheita de sêmen, foram feitas biópsias dos testículos com auxilio de agulha modelo Tru-Cut 16 gauge (16G) para biópsia. Os fragmentos foram fixados em solução fixadora de Davidson por 24 horas, depois lavados em água corrente por 20 minutos e transferidas para solução alcoólica à 70\%. Em seguida, foram processadas conforme a técnica para microscopia óptica e inclusão em parafina. Os cortes foram corados pela técnica da Hematoxilina-Eosina (HE).

Para o processamento estatístico dos dados, foi empregada a análise de variância e para a comparação das médias aplicou-se o teste de Tukey a 5\% para IMC e características quantitativas e qualitativas do sêmen.

\section{RESULTADOS}

O estudo da morfometria corpórea se faz importante para conhecermos o porte dos animais, relacionando-o com o índice de massa corpórea (IMC) variável essa utilizada para estimar a aptidão física do animal em conjunto com as variáveis reprodutivas (Chacur et al., 2006; Chacur et al., 2010). As médias das características morfométricas dos cervos utilizados no experimento estão apresentadas na Tabela 1. 
Tabela 1. Média da idade e das características morfométricas: peso corpóreo, comprimento crânio-caudal, altura de cernelha, índice de massa corpórea (IMC) e diâmetro torácico em cervos, Cervus unicolor.

\begin{tabular}{|c|c|c|c|c|}
\hline \multirow[b]{2}{*}{ Parâmetros } & \multicolumn{2}{|c|}{ Animais } & \multirow[b]{2}{*}{ C } & \multirow[b]{2}{*}{ D } \\
\hline & A & B & & \\
\hline Idade (meses) & 36 & 36 & 18 & 12 \\
\hline Peso (Kg) & 89,0 & 95,0 & 81,0 & 60,5 \\
\hline Comprimento (m) & 1,39 & 1,43 & 1,26 & 1,24 \\
\hline Altura da cernelha (m) & 0,92 & 0,89 & 0,80 & 0,81 \\
\hline $\mathrm{IMC}\left(\mathrm{Kg} / \mathrm{m}^{2}\right)$ & 105,95 & 120,25 & 126,56 & 93,07 \\
\hline Diâmetro torácico (m) & 1,01 & 1,09 & 0,88 & 0,87 \\
\hline
\end{tabular}

Com relação às características quantitativas e qualitativas do sêmen, não houve diferenças $(P>0,05)$ entre os quatro momentos de colheita, exceto na morfologia espermática da quarta colheita, para os defeitos maiores, menores e totais com elevação das porcentagens de defeitos morfológicos em relação às três primeiras colheitas, conforme a Tabela 2. Vale destacar que o método de colheita de sêmen por eletroejaculação, mostrou-se de fácil execução para a obtenção dos ejaculados. A necessidade da contenção química por sedação anestésica propiciou uma colheita de sêmen rápida.

Tabela 2. Características quantitativas e qualitativas do sêmen de cervos em distintos momentos de colheita, mantidos em cativeiro.

\begin{tabular}{|c|c|c|c|c|}
\hline \multicolumn{5}{|c|}{ Colheitas } \\
\hline Variável & 1 & 2 & 3 & 4 \\
\hline Volume (mL) & $0,75 \pm 0,28 \mathrm{~A}$ & $0,75 \pm 0,28 \mathrm{~A}$ & $0,50 \pm 0,35 \mathrm{~A}$ & $0,62 \pm 0,25 \mathrm{~A}$ \\
\hline Cor & $1,75 \pm 0,95 \mathrm{~A}$ & $1,50 \pm 1,00 \mathrm{~A}$ & $1,25 \pm 0,50 \mathrm{~A}$ & $1,25 \pm 0,50 \mathrm{~A}$ \\
\hline Aspecto & $1,75 \pm 0,95 \mathrm{~A}$ & $1,75 \pm 0,50 \mathrm{~A}$ & $1,25 \pm 0,50 \mathrm{~A}$ & $1,25 \pm 0,50 \mathrm{~A}$ \\
\hline Motilidade (\%) & $87,50 \pm 5,00 \mathrm{~A}$ & $83,75 \pm 4,78 \mathrm{~A}$ & $90,00 \pm 7,07 \mathrm{~A}$ & $83,75 \pm 4,78 \mathrm{~A}$ \\
\hline Vigor (1-5) & $5,00 \pm 0,00 \mathrm{~A}$ & $5,00 \pm 0,00 \mathrm{~A}$ & $4,75 \pm 0,50 \mathrm{~A}$ & $4,75 \pm 0,50 \mathrm{~A}$ \\
\hline Turbilhão (1-5) & $4,00 \pm 2,00 \mathrm{~A}$ & $4,00 \pm 2,00 \mathrm{~A}$ & $4,00 \pm 2,00 \mathrm{~A}$ & $4,00 \pm 2,00 \mathrm{~A}$ \\
\hline $\begin{array}{l}\text { Concentração } \\
\left(\times 10^{6} / \mathrm{mL}\right)\end{array}$ & $1137,5 \pm 892,5 \mathrm{~A}$ & $1144,1 \pm 557,6 \mathrm{~A}$ & $1140,6 \pm 699,6 \mathrm{~A}$ & $1027 \pm 763,6 \mathrm{~A}$ \\
\hline $\begin{array}{l}\text { Defeitos } \\
\text { maiores (\%) }\end{array}$ & $7,36 \pm 4,25 \mathrm{~A}$ & $5,79 \pm 2,19 A$ & $9,62 \pm 3,93 \mathrm{~A}$ & $17,00 \pm 1,87 \mathrm{~B}$ \\
\hline $\begin{array}{l}\text { Defeitos } \\
\text { menores (\%) }\end{array}$ & $10,51 \pm 3,82 \mathrm{~A}$ & $11,45 \pm 6,50 \mathrm{~A}$ & $10,78 \pm 2,79 \mathrm{~A}$ & $25,85 \pm 15,05 \mathrm{~B}$ \\
\hline $\begin{array}{l}\text { Defeitos totais } \\
\text { (\%) }\end{array}$ & $18,35 \pm 13,93 \mathrm{~A}$ & $17,25 \pm 5,81 \mathrm{~A}$ & $20,41 \pm 2,74 \mathrm{~A}$ & $47,72 \pm 17,55 B$ \\
\hline
\end{tabular}

(2) leitoso, (3) aquoso. 
Com relação à morfologia espermática, os valores médios obtidos para os defeitos maiores (cabeça isolada patológica, pequena anormal, gota proximal, defeito de peça intermediária, cauda fortemente dobrada ou enrolada e enrolada na cabeça); menores (cabeça isolada normal, retroaxial, abaxial, dobrada ou enrolada e gota citoplasmática distal) estão descritos na Tabela 3. Dessa forma, a alta porcentagem de defeitos espermáticos obtida na quarta colheita, pode estar associada ao estresse cumulativo e às contenções semanais para a obtenção dos ejaculados, semelhantes aos descritos por Cheng et al. (2009).

Tabela 3. Porcentagens de defeitos maiores, menores e totais nas quatro colheitas de sêmen em cervos sambar.

\begin{tabular}{ccccc}
\hline Animal & Colheita & $\begin{array}{c}\text { Defeitos } \\
\text { Maiores }\end{array}$ & $\begin{array}{c}\text { Defeitos } \\
\text { Menores }\end{array}$ & Defeitos Totais \\
\hline A & 1 & 5,46 & 6,72 & 12,18 \\
A & 2 & 5,5 & 6,5 & 12 \\
A & 3 & 6,22 & 3,82 & 10,04 \\
A & 4 & 14,21 & 25 & 39,21 \\
B & 1 & 3,27 & 19,62 & 22,89 \\
B & 2 & 4,67 & 5,6 & 10,27 \\
B & 3 & 7,88 & 6,89 & 14,77 \\
B & 4 & 7,35 & 13,72 & 21,07 \\
C & 1 & 4,48 & 12,55 & 17,03 \\
C & 2 & 14,07 & 7,28 & 21,35 \\
C & 3 & 9,86 & 9,86 & 19,72 \\
C & 4 & 10,09 & 13,46 & 23,55 \\
D & 1 & 16,25 & 14,77 & 31,02 \\
D & 2 & 16,98 & 14,62 & 31,06 \\
D & 3 & 15,19 & 27,45 & 42,64 \\
D & 4 & 19,6 & 46,56 & 66,16 \\
\hline
\end{tabular}

A análise microscópica dos testículos dos cervos foi realizada e o material processado pela técnica de hematoxilina-eosina (HE) mostrando integridade do arcabouço dos túbulos seminíferos, observada por meio da presença das células da linhagem espermatogênica disposta em camadas homogêneas (Fig. 1). 


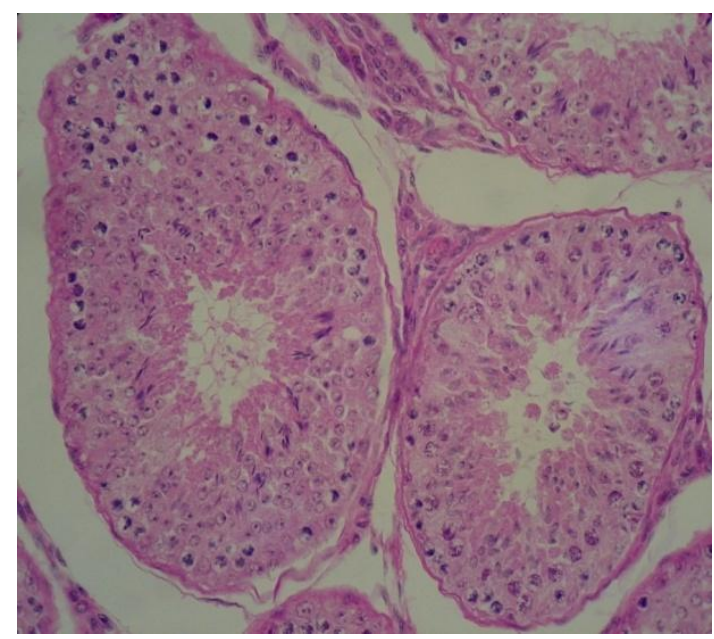

Figura 1. Corte de testículo, mostrando túbulos seminíferos, com o epitélio germinativo íntegro HE (400x) de cervos, Cervus unicolor.

\section{DISCUSSÃO}

As estratégias de manejo reprodutivo que está intimamente relacionado às boas condições nutricional do animal (Paranhos da Costa, 2000). Portanto nesse estudo evidenciou a qualidade da nutrição através dos resultados das características morfométricas apresentadas.

A literatura destaca que o estresse das condições do cativeiro é causado pelo aprisionamento, redução da liberdade e pela imposição da convivência constante com vários indivíduos, e que na natureza, estes animais vivem a maior parte do tempo isolados (Duarte e Merino, 1997). Dentro desse raciocínio do estresse do cativeiro e dos fatores estressantes associados, uma alta porcentagem de defeitos totais $(40,9 \pm 10,42 \%)$ foi relatada em cervos no Brasil (Abreu et al., 2009).

No presente estudo, o volume dos ejaculados foi semelhante ao observado em machos sexualmente maturos "Formosan Sika deer" e "Formosan Sambar deer" com 0,5 $\pm 0,4 \mathrm{~mL}$ (Cheng et al., 2004) e diferiu do relatado por Abreu et al. (2009) com 0,91 $\pm 0,68 \mathrm{~mL}$ em Mazama nana e Ascher et al. (2000) com volume de 1,5 $\pm 0,6 \mathrm{~mL}$ em cervos Dama dama. O volume dos ejaculados pode variar conforme a espécie, idade, peso, frequência de ejaculação e tamanho do aparelho reprodutor dos cervos (Ascher et al., 2000; Cheng et al., 2004; Abreu et al., 2009).

As motilidades médias obtidas no presente estudo foram superiores às descritas por Cheng

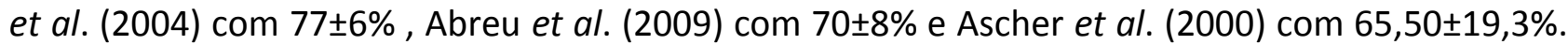

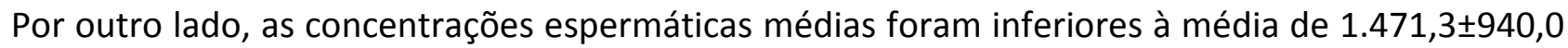
$\mathrm{x} 10^{6} / \mathrm{mL}$, Abreu et al. (2009) com $1.536 \pm 351 \times 10^{6} / \mathrm{mL}$ e Ascher et al. (2000) com $2.100 \pm 1.400$

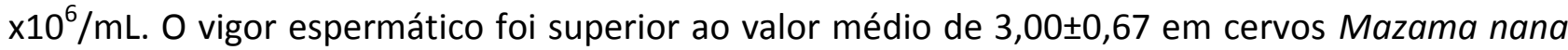
relatado por Abreu et al. (2009). A concentração espermática pode oscilar devido ao método de 
colheita por eletroejaculação (Chacur, 2012; Chacur et al., 2012) e ao estresse do cativeiro (Ascher et al., 2000; Cheng et al., 2004; Abreu et al., 2009).

Nas espécies dos veados somente os dominantes produzem sêmen de boa qualidade (Comizzoli et al., 2000). Este fato está relacionado com o comportamento sexual e social a partir do princípio de setembro, época do inicio da ciclicidade reprodutiva, onde se verifica a presença de fêmeas na fase de estro (Coucelo, 1986).

\section{CONCLUSÃO}

Boa qualidade espermática foi observada no mês de novembro (primavera), nas três primeiras colheitas. As características dos ejaculados não diferiram entre as colheitas sucessivas, exceto a morfologia espermática que se elevou na quarta colheita, possivelmente devido ao estresse das contenções semanais sucessivas. Tratando-se de animais cativos, a qualidade espermática está relacionada ao bem-estar e à nutrição, fator de destaque, onde a oferta e distribuição de alimentos garantem ao animal condições de expressar seu potencial produtivo e reprodutivo.

\section{REFERÊNCIAS}

ABREU, O.C.; MARTINEZ, C.A.; MORAES. W et al. Características reprodutivas de veado-bororó-dosul ou veado-mão-curta (Mazama nana). Pesq. Vet. Brás., v.29, n.12, p.993-998, 2009.ASCHER, G.W.; BERG, D.K.; EVANS, G. Storage of semen and artificial insemination in deer. Animal Reproduction. Science., v.62, p.195-211, 2000.

CHACUR, M.G.M. Seminal Plasma Proteins as Potential Markers of Relative Fertility in Zebu Bulls (Bos taurus indicus), Rijeka: In Tech, 2012, Electrophoresis ISBN- 9806533071171.

CHACUR, M. G. M. Estresse térmico em touros bufalinos Bubalus bubalis, avaliações das características fisiológicas da reprodução. 2000. Tese (Doutorado em Medicina Veterinária). Departamento de Reprodução Animal e Radiologia Veterinária - Universidade Estadual Paulista, Botucatu. 2000.

CHACUR, M.G.; ARAUJO, M.C.; KRONKA, S. Características seminais, corpóreas e anatômicas do aparelho reprodutor de reprodutores da raça Canchim aos 14 e 48 meses de idade. Arquivo de Ciências Veterinária e Zootecnia da UNIPAR., v.9, p.21-27, 2006.

CHACUR, M.G.M.; AURÉLIO, P.T.F.; OBA, E. et al. Influência de um nutracêutico no sêmen, testosterona, cortisol, eritrograma e peso corpóreo em touros jovens Bos taurus indicus. Semina Agrárias, v.31, p.439-450, 2010.

CHACUR, M.G.M; MIZUSAKI, K.T.; SANTOS F.H. et al. Influência da estação do ano nas características do sêmen e na concentração de hormônios em touros Nelore e Simental. Arq. Bras. Med. Vet. Zootec., v.64, n.3, p.540-546, 2012. 
CHACUR, M. G. M.; OBA, E. Heat stress in buffalo bulls Bubalus bubalis, evaluations of reproduction phisiologycal characteristics. Veterinária Notícias, Uberlândia, v. 11, n. 1 , p. 111-112, 2005.

CHENG, F.P.; WU, J.; CHAN, J et al. The effect of different extenders on post-taw sperm survival, acrosomal integrity and longevity in cryopreserved semen of Formosan Silka deer and Formosan Samba deer. Theriogenology., v.61, p.1605-1616, 2004.

COMIZZOLI, P.; MERMILLOD P.; MAUGET, R. Reproductive biotchnologies for endangered mammalian species. Reprod. Nutr. Dev., v.40, p.493-504, 2000.

COUCELO, M. Bases biológicas essenciais para o ordenamento do veado. Lisboa, 1986. 64 p. Final report - Instituto Superior de Agronomia, Universidade Técnica de Lisboa.

DESNOYERS, L. Characterization of the mayor proteins of bovine seminal fluid by two dimensional polyacrulamide gel eletroforesis. Molec. Reprod. Develop., v.37, p.425-443, 1994.

DUARTE, J. M.B.; MERINO, M.L. Tecnologia da reprodução para a propagação e conservação de espécies ameaçadas de extinção. In: DUARTE J.M.B. Biologia e Conservação de cervídeos sulamericanos: Blastocerus, Ozotoceros e Mazama. Jaboticabal, SP: FUNEP, p.228-238, 1997.

ESPANIER, R. Characterizaction of a new bioactive protein from bovine seminal fluid. Biochemical and Biophsical Reseach Communications. Gattingen., v.179, n.2, p.1006-1010, 1991.

MAIA, M. J. F. A. Contribuição para o estudo de algumas espécies de cervídeos (Cervus elaphus, Cervus canadensis e Dama dama) no Jardim Zoológico de Lisboa e Tapada Nacional de Mafra. Santarém, 1993. 119 p. Relatório de Estagio de Produção Animal - Instituto Politécnico de Santarém, Escola Superior Agrária de Santarém, Santarém.

MANJUNATH, P. Purification and biochemical characterizaction of three major acidic proteins (BSP-A1, BSP-A2 and BSP-A3) from bovine seminal plasm. European Journal of Biochemistry, Berlin., v.241, p.685-692, 1987.

PARANHOS DA COSTA, M. J. R. Ambiência na produção de bovinos de corte a pasto. Anais de Etologia., v.18, p. 26-42, 2000.

POCAY, P.L.B. et al. Respostas fisiológicas de cavas holandesas predominantemente brancas e predominantemente negras sob radiação solar direta. ARS VETERINARIA., v. 17, n.2, p.155-161, 2001.

SALVADOR, D.F.; DIAS, J.C.; VALE FILHO, V.R. et al. Perfil andrológico de touros da raça Nelore com três e quatro anos de idade, criados extensivamente em condições do estado do Mato Grosso do Sul. Rev. Bras. Reprod. Anim., v.26, p.64-67, 2002.

VALE FILHO, V.R.; PINHEIRO, L.E.L.; BASUR, P.K. Reproduction in zebu cattle. In: MORROW, D.A (2Ed). Current therapy in theriogenology. Philadelphia: W.B. Saunders Company, 1986. p. 437-442. VAN SOEST, P.J. Nutricional ecology of the ruminant (2Ed). New York: Cornell University, 1994. p.476. 